Note

\section{Kinetics of Thermal Changes in Absorbance of a Solution System of Soybean 11S Protein}

\author{
Ken Watanabe \\ Laboratory of Food Chemistry, \\ Department of Agricultural Chemistry, \\ Faculty of Agriculture, \\ Tokyo Noko University, \\ Fuchu, Tokyo 183, Japan
}

Received January 30, 1986

Soy milk or soy protein solutions are necessarily heated in food processing, whereby its physical properties are greatly changed; these changes, mainly due to the $11 \mathrm{~S}$ component, were reported to be induced stepwise. ${ }^{1,2}$ ) Ultraviolet absorption of the protein solution indicates a thermal profile correlated with the distribution of hydrophobic areas on an $11 \mathrm{~S}$ globulin molecule, ${ }^{3)}$ and it may also reflect the state of heat treated solutions more quantitatively, because it does not need any additional reaction for measurement.

I measured the ultraviolet absorption of a solution system of soybean $11 \mathrm{~S}$ protein and calculated the rate constants of its increase and subsequent decrease by heating from the equation of consecutive reaction kinetics.

Soybean 11S component was isolated from defatted soybean meal ${ }^{4)}$ and dissolved in standard phosphate buffer. The final protein concentration of the solution was adjusted to $0.05 \%$, the ionic strength to 0.5 , and the $\mathrm{pH}$ to 7.6. Five milliliters of the protein solution was placed in a $12 \times 120 \mathrm{~mm}$ test tube covered with a rubber cap and brought to room temperature just before heating. The samples, while being constantly stirred, were kept in a water bath at various temperatures. After the desired periods of heating, the tubes were immersed in an ice bath for $30 \mathrm{sec}$ to cool as quickly as possible and left for an hour at room temperature. Ultraviolet difference spectra were obtained with a Shimadzu model UV-200 spectrophotometer at $20^{\circ} \mathrm{C}$. The differences in absorbance between native and heat treated samples were measured at the wavelength at which the absorbance OD is maximum.

A typical ultraviolet difference spectrum of heat treated $11 \mathrm{~S}$ protein solution is shown in Fig. 1. As the temperature was raised, the absorbance increased; this increase was observed over all wavelengths measured. The absorbance had a peak at $290 \mathrm{~nm}$ at all temperatures and was proportional to the concentration of the samples under the same treatment. While the sample was heated it remained transparent, but turbidity and a precipitate appeared when it was cooled. After centrifugation to remove the turbidity and precipitate, absorbance of the supernatant was measured, and the variations of $\mathrm{OD}_{290}$ with heating time at each temperature are shown in Fig. 2. The absorbance initially increased with heating time, reached a maximum, and then decreased when heated above $87^{\circ} \mathrm{C}$.

The curve at $100^{\circ} \mathrm{C}$ had a maximum at about $2 \mathrm{~min}$ which agreed with previous reports on the thermal change in ultracentrifugal pattern, ${ }^{1)}$ in relation to sulfhydryl groups, ${ }^{5)}$ and on solubility changes with the time $\mathrm{lag}^{2)}$; this may therefore be compatible with the concept of a thermal denaturation pathway including plural steps reported

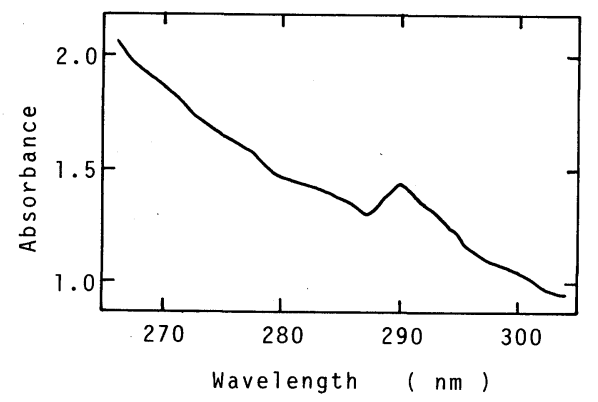

FIG. 1. Typical UV Difference Spectrum of Heat Treated 11S Protein Solution.

The solution was heated at $90^{\circ} \mathrm{C}$ for $5 \mathrm{~min}$.

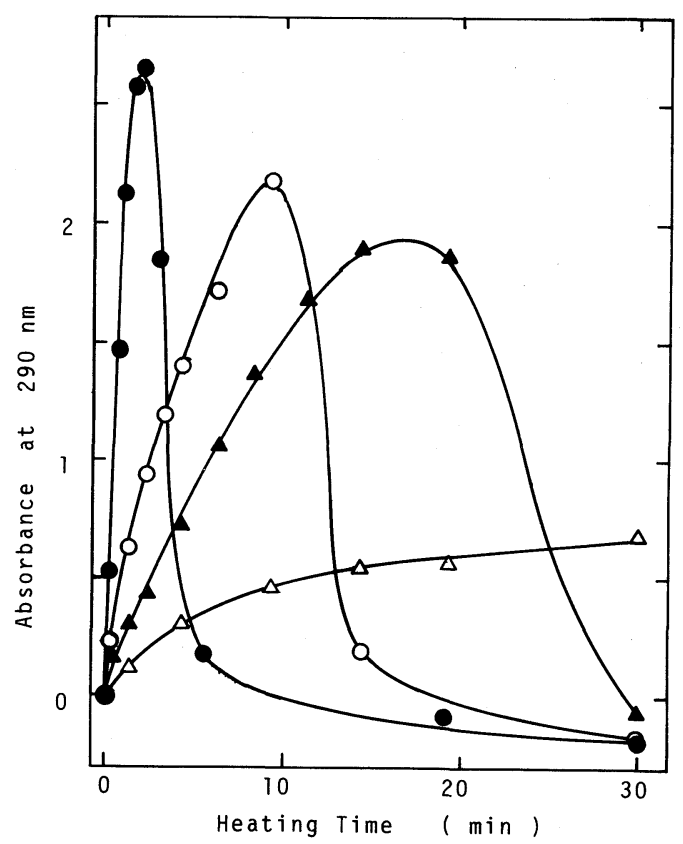

FIG. 2. Courses of Absorbance of 11S Protein Solution at $290 \mathrm{~nm}$ during Heat Treatment.

Symbols are: $(\bigcirc) 100^{\circ} \mathrm{C},(\bigcirc) 90^{\circ} \mathrm{C},(\boldsymbol{\Delta}) 87^{\circ} \mathrm{C}$, and $(\triangle)$ $80^{\circ} \mathrm{C}$. 
above. $^{1,2)}$ The results in Fig. 2 are not always consistent with the above schemes, but correlate excellently with the theoretical expectations of consecutive first order reaction kinetics consisting of two steps, according to the following equations;

when $k_{1} \neq k_{2}$,

$$
B=A_{0} \frac{k_{1}}{k_{2}-k_{1}}\left(\mathrm{e}^{-k_{1} t}-\mathrm{e}^{-k_{2} t}\right)-B_{0}\left(1-\mathrm{e}^{-k_{2} t}\right)
$$

and when $k_{1}=k_{2}=k$,

$$
B=A_{0} k t \mathrm{e}^{-k t}-B_{0}\left(1-\mathrm{e}^{-k t}\right)
$$

where

$B=$ concentration of intermediate in thermal changes of $11 \mathrm{~S}$ protein measured as absorbance at $\mathrm{OD}_{290}$ after time ' $t$ '

$A_{0}=$ initial value of $A$, concentration of native $11 \mathrm{~S}$ protein measured at $\mathrm{OD}_{290}$

$B_{0}=$ initial value of $B$ measured at $\mathrm{OD}_{290}$

$k_{1}=$ the reaction rate constant of the first step (from state A to B)

$k_{2}=$ the reaction rate constant of the second step (from state $\mathrm{B}$ to $\mathrm{C}$ )

The solute in state $\mathrm{C}$ may reduce the absorbance by refolding ${ }^{6)}$ or coagulation.

The values for $A_{0}, B_{0}, k_{1}$, and $k_{2}$ were numerically calculated as parameters in the equation by Marquardt's nonlinear least-squares method with a personal computer. Values of 6.75 and 0.185 were obtained for $A_{0}$ and $B_{0}$, respectively, at all temperatures measured. Arrhenius plots summarizing the results of calculation on $k_{1}$ and $k_{2}$ are shown in Fig. 3, from which the apparent activation energies were calculated at $50.5 \mathrm{kcal} \cdot \mathrm{mol}^{-1}$ for the first step in the process and $26.6 \mathrm{kcal} \cdot \mathrm{mol}^{-1}$ for the second step. The frequency factors were $342 \times 10^{25} \mathrm{sec}^{-1}$ and $238 \times 10^{11} \mathrm{sec}^{-1}$, respectively.

These values are within the range reported for other proteins for foodstuffs. ${ }^{7,8)}$ The rate of the first step is more dependent on temperature than is the second, and below $80^{\circ} \mathrm{C}$ the rate limiting process of reaction may be regarded as a single step, because $k_{1}$ is far smaller than $k_{2}$.

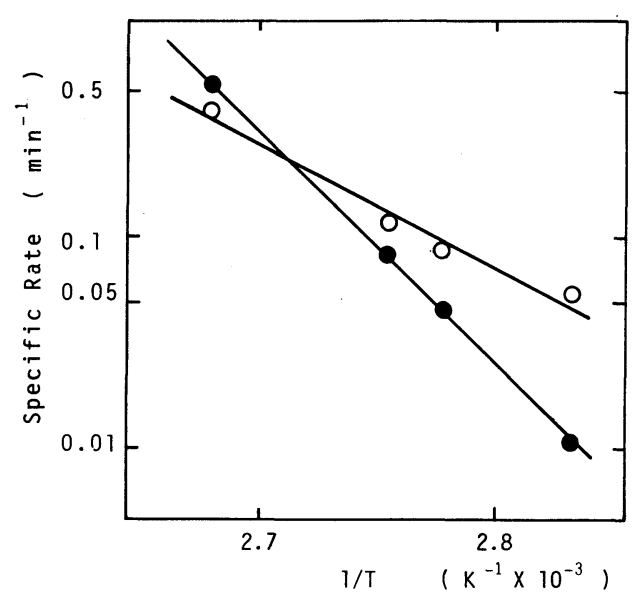

FIG. 3. Arrhenius Plots for the Thermal Changes in $\mathrm{OD}_{290}$ of $11 \mathrm{~S}$ Protein Solution.

Symbols are: (O) the first step and $(\bigcirc)$ the second step.

\section{REFERENCES}

1) W. J. Wolf and T. Tamura, Cereal Chem., 46, 331 (1969).

2) T. Mori, T. Nakamura and S. Utsumi, J. Food Sci., 47, 26 (1981).

3) T. Yamagishi, F. Yamauchi and K. Shibasaki, Agric. Biol. Chem., 45, 459 (1981).

4) V. H. Thanh, K. Okubo and K. Shibasaki, Plant Physiol., 56, 19 (1975).

5) K. Saio, M. Kajikawa and T. Watanabe, Agric. Biol. Chem., 35, 890 (1971).

6) T. Yamagishi, T. Tomisawa and F. Yamauchi, Agric. Biol. Chem., 47, 2475 (1983).

7) J. W. Pence, A. Mohammad and D. K. Mecham, Cereal Chem., 47, 115 (1953).

8) W. E. Eipson, N. Singh and S. P. Manjrekar, J. Food Sci. Technol., 11, 66 (1974). 